\title{
Dominique Millet-Gérard, La Prose transfigurée
}

\section{Emanuele Kanceff}

\section{(2) OpenEdition}

\section{Journals}

\section{Édition électronique}

URL : http://journals.openedition.org/studifrancesi/30691

DOI : 10.4000/studifrancesi.30691

ISSN : 2427-5856

\section{Éditeur}

Rosenberg \& Sellier

\section{Édition imprimée}

Date de publication : 1 avril 2006

Pagination : 189-190

ISSN : 0039-2944

\section{Référence électronique}

Emanuele Kanceff, «Dominique Millet-Gérard, La Prose transfigurée », Studi Francesi [En ligne], 148 $(X L X \mid I)$ | 2006, mis en ligne le 30 novembre 2015, consulté le 19 avril 2021. URL : http://

journals.openedition.org/studifrancesi/30691 ; DOI : https://doi.org/10.4000/studifrancesi.30691

Ce document a été généré automatiquement le 19 avril 2021.

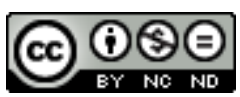

Studi Francesi è distribuita con Licenza Creative Commons Attribuzione - Non commerciale - Non opere derivate 4.0 Internazionale. 


\title{
Dominique Millet-Gérard, La Prose transfigurée
}

\author{
Emanuele Kanceff
}

\section{RÉFÉRENCE}

DOMINIQUE MILLET-GÉRARD, La Prose transfigurée, Vingt études en hommage à Paul Claudel pour le cinquantenaire de sa mort, Paris, PUPS (Presses universitaires de Paris Sorbonne), 2005, pp. 468.

1 Certamente la scrittura di Claudel si rifiuta diessere incasellata nella distinzione classica tra prosa e versi. Prosa di grande sontuosità, che si modella sugli effetti dell'antica prosa d'arte, ne costituisce tuttavia una ricostruzione profondamente originale, che si accompagna sempre ad una profonda meditazione sulla creazione artistica. Gli studi qui raccolti vogliono fare il punto sulle fonti dell'ispirazione claudeliana e determinare l'etetica della sua scrittura.

2 Questo folto apparato di riflessioni che l'Autrice dedica a Paul Claudel è strutturato in tre parti strettamenger complementari. Nella prima, «Compagnonnages, modèles et regards croisés», si esaminano, in sei capitoli che formano altrettanti studi puntuali, le strade parallele, le mutue influenze, le riflessioni comuni che hanno messo in relazione Claudel con suoi illustri contemporanei, da Mallarmé a Mauriac, da Léon Bloy ad André Rouveyre al P. Maydieu, suo amico e collaboratore.

3 La seconda parte affronta il tema di CLaudel e l'Europa, con suggestivi accostamenti a D'Annunzio, a Wagner, a Dante, a S. Ignazio di Loyola, a Gregorio Magno. Dopo il dialogo con i grandi scrittori del passato, una riflessione più specialmente tematica si sviluppa nella terza parte del volume, in cui questi «Regards comparatistes: l'Europe intellectuelle et spirituelle» spaziano sulle tematiche fondamentali della scrittura e della meditazion claudeliane: il sublime, il riso, la poetica sacramentale, il peccato, la metafisica del Bello, l'ordinamento della parola poetica, la trasfigurazione nel suo 
teatro e nel suo pensiero, il ruolodell'esegesi biblica, il significato del coro e della forma alterna nella sua riflessione estetica.

4 Questi venti studi qui riuniti sono stati scritti e pubblicati tra il 1984 e il 2001; tutti singolarmente interessanti e originali, prendono tuttavia una ltro spessore così giustapposti a formare i differenti capitoli di un affresco unico e affascinante. 